\title{
SURVEY OF INORGANIC COMPONENTS IN ATMOSPHERIC PARTICLES OF THREE URBAN AREAS CAUSED BY WINTER ENERGY CONSUMPTION IN CHINA AND JAPAN
}

\author{
QINGYUE WANG \& WEIQIAN WANG \\ Graduate School of Science and Engineering, Saitama University, Japan
}

\begin{abstract}
Today, countries around the world are continuing to advance economically, putting a great strain on the ability of the natural environment to process the high level of pollutants being created. In recent years, the increase in fossil fuel consumption, especially in China, is significant, due to advancing economic development. Air pollution, such as suspended particle matter emitted from anthropogenic sources, has already become a serious regional problem for the urban environment, and could be an important inhibitory factor for sustainable development. In this paper, the atmospheric inorganic compositions of three urban areas - Saitama city in the Tokyo metropolitan area, Nagasaki city in Japan and Shanghai metropolitan area in China - were determined during the winter of 2015. The results showed that water-soluble components such as sulfate ion $\left(\mathrm{SO}_{4}{ }^{2-}\right)$, nitrate ion $\left(\mathrm{NO}_{3}{ }^{-}\right)$and potassium ion $\left(\mathrm{K}^{+}\right)$, as secondary particles of anthropogenic combustion sources, increase in the order of Shanghai $>$ Nagasaki > Saitama, and are several times higher in Shanghai compared with those of the other sampling sites. It was confirmed that serious air pollution events create nitrogen oxides, and sulfur oxides are caused by fossil fuel consumption. It might be possible that the urban air pollutants of fossil-fuel-burning sources were transported to Japan by "long-range transportation". As we can see from the analytical results from the Shanghai urban area, the main source of anthropogenic pollution is commonly the exhaust emitted from motor vehicles. However, trace elements such as arsenic (As), selenium (Se), vanadium (V) and nickel (Ni) of coal and petroleum oil combustion were higher in the Nagasaki urban area than in the Saitama urban area. It was indicated that the urban air pollution in Shanghai, due to the presence of inorganic components caused by seasonal energy consumption, were much higher than in Japan during the winter sampling periods. It could be considered that the air pollutants were transported to Japan via long-range transportation. According to these experimental findings, it is evident that China's energy structure requires improvement if progress is to be made in sustainable development.
\end{abstract}

Keywords: sustainable development, inorganic components, suspended particle matter, energy combustion, Shanghai, China, Nagasaki, Saitama, Japan.

\section{INTRODUCTION}

In recent years, there has been a significant increase in fossil fuel consumption in East Asia due to economic development, particularly coal consumption, which is China's main energy resource - China accounted for half of the world's coal consumption in 2015 [1]. In China, the direct consumption of coal accounts for a large part of its utilization, and coal combustion is a major mode of consumption [2]. Fossil fuel combustion results in large quantities of primary particle emissions to the atmosphere, as well as gaseous compounds that convert to particles within hours to days after emission. Low-grade coal, raw and refined petroleum products and natural gas are burned throughout the world to create electricity, refine metals and organic materials, heat buildings, cook food and provide transportation. Fossil fuel combustion is also a major emitter of sulfur dioxides and nitrogen oxides - gases that react with other constituents in the atmosphere to create secondary sulfate and nitrate particles [3]. 
China is already the second largest producer of greenhouse gases, and acid rain falls on one third of the total area of this country; one study in China suggests that air pollution has led to the loss of over 12.7 billion dollars during the past 20 years of economic development [4]. In 2015, the World Health Organization reported that at least one in eight people die of air pollution globally. Therefore, air pollution has become the world's largest environmental health risk [5].

Three urban areas in East Asia were selected for this study. Shanghai is one of the four direct-controlled municipalities of China and the most populous city in the world, with a population of more than 24 million as of 2017. It is a global financial center and transport hub, with a globally prosperous container port [6]. The Kanto region is the most highly developed, urbanized and industrialized part of Japan. Saitama is in the Greater Tokyo Area, lying 15-30 km north of central Tokyo, and many of its residents commute into Tokyo. As of 1 February 2016, the city had an estimated population of 1,226,65 and a population density of 5830 persons per $\mathrm{km}^{2}$. Saitama's economy principally comprises commercial business. The city is one of many commercial centers of the Greater Tokyo area and serves Saitama Prefecture, North Kanto and northeast Honshu [7]. Nagasaki prefecture is located at the westernmost point of Japan, with geographical features that are close to China's mainland.

In this study, the atmospheric inorganic compositions of three urban areas - Shanghai, Nagasaki and Saitama - are the main study objective. Size-segregated samples of suspended particulate matter (SPM) were collected using a new Andersen high-volume air sampler model, equipped with five stages of an Andersen impactor. Water-soluble components and trace elements in SPM were analyzed as the main inorganic components. The secondary ionic particles and the enrichment factors (EFs) were used to analyze the original sources. The back-trajectory analysis of the Hybrid Single Particle Lagrangian Integrated Trajectory Model on the National Oceanic and Atmospheric Administration (NOAA HYSPLIT model) was used to determine the effects of long-range transportation. And finally, the ion contents, trace element concentrations, EFs, etc. are summarized, and the influence of energy consumption on atmosphere quality and long-distance transportation is discussed. This paper concludes with discussing the importance of air quality and energy consumption for the development of urban sustainability.

\section{MATERIAL AND METHODS}

\subsection{Sampling periods in three urban sites for SPM}

Three urban sites (Fig. 1) were selected for sampling, located in Shanghai city, Saitama city and Nagasaki city in East Asia, with the same sampling periods from 25 November to 7 December 2015.

The Shanghai urban sampling site was located in Shanghai University, Baoshan District, Shanghai, China. Ambient particle samples were collected from the rooftop (approximately $30 \mathrm{~m}$ above the ground level) of the "D building" on the suburban campus of Shanghai University in Shanghai China $\left(31.19^{\circ} \mathrm{N}, 121.39^{\circ} \mathrm{E}\right)$, which was situated very close to a residential zone and roadside. The sampling site was about $1.5 \mathrm{~km}$ from the nearest highway with heavy traffic and was surrounded by residential areas.

The Saitama urban sampling site $\left(35.87^{\circ} \mathrm{N}, 139.61^{\circ} \mathrm{E}\right)$ was located in Saitama University, close to National Route 463, which, according to the survey results, experiences about 30,000-35,000 vehicles per day. In order to highlight the characteristics of an urban sampling site, major traffic lines and high-traffic areas were considered as a good sampling site. 


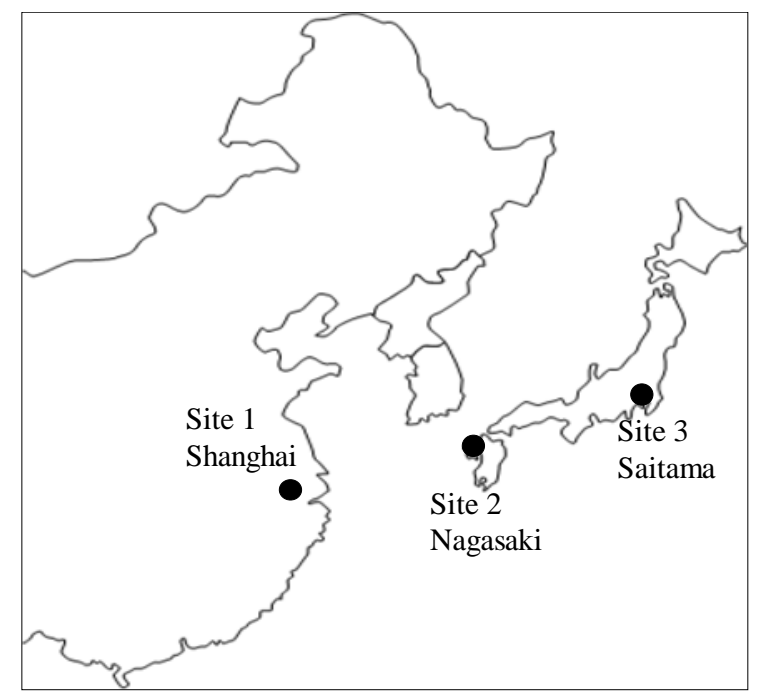

Figure 1: Three urban sampling sites.

The Nagasaki urban sampling site $\left(32.91^{\circ} \mathrm{N}, 129.74^{\circ} \mathrm{E}\right)$, Nagasaki prefecture, was located at the westernmost point of Japan, with geographical features that are close to China's mainland. Therefore, air pollution originating from China's mainland easily affected the sampling site's levels of air pollution; however, there were trees around the main sampling site, the traffic volume was small and the industrial area had not been developed. Also, because it was a summit point (altitude $533 \mathrm{~m}$ ), the direct influence of pollutants generated in the country was considered to be extremely low. Based on these conditions, Nagasaki Prefecture's forest located on the island of Kyushu was selected as a sampling point, outside Nagasaki city.

\subsection{Air sample collection of SPM}

The sampling campaign was conducted for three weeks over the summer season, from 25 November to 7 December 2015. Size-segregated samples of SPM were collected on the quartz fiber filters (Pallflex Product, 2500QATUP) using a new Andersen high-volume air sampler model (HV-1000R, Shibata Co., Tokyo, Japan) equipped with a five-stage Andersen impactor (Shibata Co., Tokyo, Japan). Five-stage size-segregated suburban SPM samples (particle sizes ranging $\leq 1.1,1.1-2.0,2.0-3.3,3.3-7.0$ and $\geq 7.0 \mu \mathrm{m}$ in aerodynamic diameter) were collected with a flow rate of $0.566 \mathrm{~m}^{3} / \mathrm{min}$. After collection, all filter samples were dried for about 24 hours in a drying oven to evaporate excess water; the filters were then wrapped in cleaned aluminum foil, sealed in plastic bags and then stored at $-30^{\circ} \mathrm{C}$ until being submitted for analysis.

\subsection{Determination of water-soluble ions in SPM}

Water-soluble ions were extracted from quartz glass filters with cutting $8 \mathrm{~mm} \varphi$ out of 10 pieces of the filters. Then, the filters were transferred to dark-brown ultrasonic extraction bottles with $10 \mathrm{ml}$ of ultrasonic water. Water-soluble inorganic ions were dissolved with ultrasonic treatment $\left(30 \mathrm{~min}\right.$ and $25^{\circ} \mathrm{C}$ ). Every $0.6 \mathrm{ml}$ ions solutions were filtered with 
$0.20 \mu \mathrm{m}$ filters (DISMIC-13C, Advantec) and injected into a Liquid chromatograph (IC, Liquid Chromatograph, Shimadzu Co., Tokyo, Japan) for anions (chloride ion $\left(\mathrm{Cl}^{-}\right), \mathrm{NO}_{3}{ }^{-}$ and $\mathrm{SO}_{4}{ }^{2-}$ ) with Multication Standard III (Wako 137-14611, Japan) and DionexICS-1600 (Thermo Fisher Scientific, Co., Japan) for cations (sodium ion $\left(\mathrm{Na}^{+}\right)$, ammonium ion $\left(\mathrm{NH}_{4}^{+}\right)$, calcium ion $\left(\mathrm{Ca}^{2+}\right)$, potassium ion $\left(\mathrm{K}^{+}\right)$and manganese ion $\left.\left(\mathrm{Mg}^{2+}\right)\right)$ with the Multication Standard Solution Ш (134-14621, Wako Chemicals, Co., Japan). Each sample was tested three times.

2.4 Determination of the trace elements in SPM by inductively coupled plasma mass spectrometry (ICP-MS)

The suitable AHV filters were extracted using $5.0 \mathrm{ml}$ nitric acid $\left(\mathrm{HNO}_{3}\right), 1.0 \mathrm{ml}$ hydrogen peroxide $\left(\mathrm{H}_{2} \mathrm{O}_{2}\right)$, $2.0 \mathrm{ml}$ hydrofluoric acid $(\mathrm{HF})$ in a polytetrafluoroethylene (PTFE) vessel with high temperature and pressure $\left(105^{\circ} \mathrm{C}, 30 \mathrm{~min} ; 170^{\circ} \mathrm{C}, 2 \mathrm{~h}\right)$. Finally, the samples were filled to $10 \mathrm{ml}$ with $2 \% \mathrm{HNO}_{3}$. The trace element concentrations were analyzed using ICP-MS (model Agilent 7700) for the crustal elements such as sodium (Na), magnesium $(\mathrm{Mg})$, aluminum $(\mathrm{Al})$, potassium $(\mathrm{K})$, calcium $(\mathrm{Ca})$ and iron $(\mathrm{Fe})$; and for trace elements such as zinc $(\mathrm{Zn})$, lead $(\mathrm{Pb})$, nickel $(\mathrm{Ni})$, manganese $(\mathrm{Mn})$, chromium $(\mathrm{Cr})$, titanium $(\mathrm{Ti})$, copper $(\mathrm{Cu})$, arsenic (As), selenium (Se), cadmium (Cd), antimony (Sb) and vanadium (V).

\subsection{Backward-trajectory calculations of air mass}

To identify the air mass and potential sources of the particulate contributing to pollution at the three sampling sites, we calculated air mass trajectories during the study periods. The HYSPLIT model was used to determine a database of air mass backward trajectories by calculating data using the Global Data Assimilation System (GDAS) from the NOAA Air Resources Laboratory's Web server. Each air mass backward trajectory was calculated as each 24 hours' air mass backward trajectory, starting from -120 hours, and the starting point was calculated with the altitude of $50 \mathrm{~m}$, to match the Shanghai ambient particulate sampling point. Calculations were made over the winter season period, from 25 November to 7 December 2015.

\section{RESULTS AND DISCUSSION}

3.1 The average ionic concentrations and variation patterns in SPM of Shanghai (China), Nagasaki and Saitama (Japan)

Seven species of ions in size-segregated samples of suspended particular matter collected during the November-December 2015 sampling campaign periods at Shanghai, Nagasaki and Saitama were found, as shown in Fig. 2. The average concentrations of total ionic concentrations in TSP were $47.05 \mu \mathrm{g} / \mathrm{m}^{3}$ in Shanghai, $8.02 \mu \mathrm{g} / \mathrm{m}^{3}$ in Nagasaki and $3.02 \mu \mathrm{g} / \mathrm{m}^{3}$ in Saitama; in $\mathrm{PM}_{1.1}$, we found $28.70 \mu \mathrm{g} / \mathrm{m}^{3}$ in Shanghai, $5.56 \mu \mathrm{g} / \mathrm{m}^{3}$ in Nagasaki and $1.50 \mu \mathrm{g} / \mathrm{m}^{3}$ in Saitama. And it was obvious that $\mathrm{NH}_{4}{ }^{+}, \mathrm{NO}_{3}{ }^{-}$and $\mathrm{SO}_{4}{ }^{2-}$, as the main secondary ions, were mainly located in $\mathrm{PM}_{1.1}$ at three sampling sites. Compared to Nagasaki, which is suburban, the urban areas of Shanghai and Saitama had high concentrations of $\mathrm{NO}_{3}{ }^{-}$ions, while high concentrations of $\mathrm{SO}_{4}{ }^{2-}$ ions occurred in Nagasaki. Components such as $\mathrm{SO}_{4}{ }^{2-}$, $\mathrm{NO}_{3}{ }^{-}$and $\mathrm{K}^{+}$, which were thought to be anthropogenic, increased in the order of Shanghai $>$ Nagasaki > Saitama, and, compared with the two sampling points in Japan, Shanghai levels were over ten times higher, confirming that there was serious air pollution, such as nitrogen oxides and sulfur oxides, in Shanghai. 

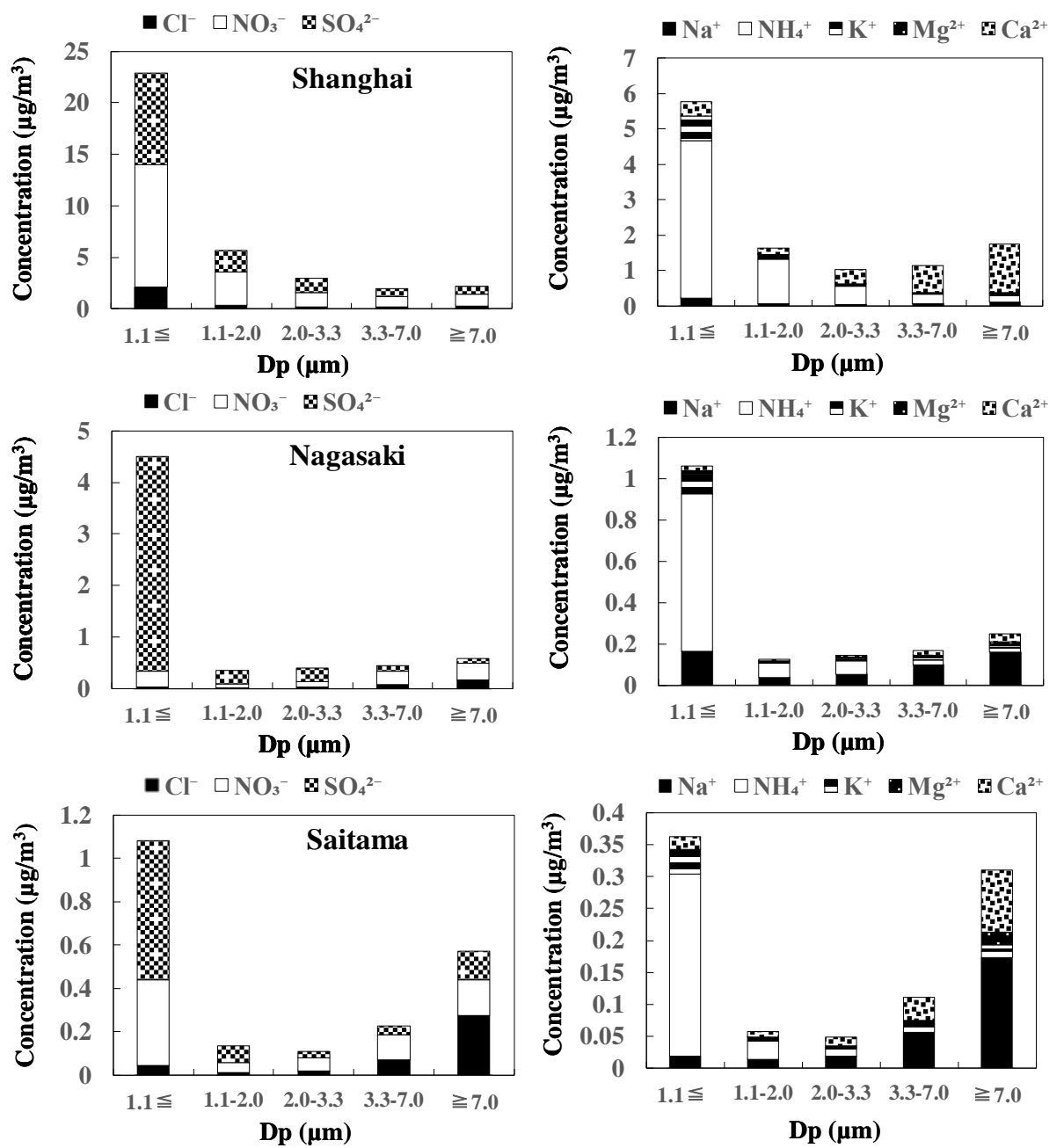

Figure 2: Seven kinds of ionic concentrations in size-segregated samples of SPM collected during November-December 2015 sampling campaign periods.

3.2 The characteristics of $\mathrm{SO}_{4}{ }^{2-}$ ions in SPM associated with anthropogenic activities

Although $\mathrm{SO}_{4}{ }^{2-}$ is a typical artificial substance, it is also known to occur in oceanic particles generated by the ocean. Nagasaki and Shanghai are situated at locations relatively close to the ocean, and marine $\mathrm{SO}_{4}{ }^{2-}\left(\mathrm{ss}_{-} \mathrm{SO}_{4}{ }^{2-}\right.$ ) and non-sea salt $\mathrm{SO}_{4}{ }^{2-}$ (nss- $\mathrm{SO}_{4}{ }^{2-}$ ) were calculated. Here, nss- $\mathrm{SO}_{4}{ }^{2-}$ was indirectly determined based on eqn (1):

$$
\left(\text { nss- } \mathrm{SO}_{4}{ }^{2-}\right)=\left(\mathrm{SO}_{4}{ }^{2-}\right)-\left(\mathrm{Na}^{+}\right) \times\left(\mathrm{SO}_{4}{ }^{2-} / \mathrm{Na}^{+}\right)_{\text {seasalt }} .
$$

Eqn (1) was calculated assuming that 1) the chemical composition of seawater and sea salt particles were the same and 2) the particulate matter (PM) sample of $\mathrm{Na}^{+}$was assumed to be derived from sea salt. Concentrations in sea water were set to $\mathrm{Na}^{+}: 468.3 \mathrm{mmol} / \mathrm{L} \mathrm{SO}_{4}{ }^{2-}$ : 
$28.23 \mathrm{mmol} / \mathrm{L}$; and $\mathrm{Ca}^{2+}: 10.12 \mathrm{mmol} / \mathrm{L}$. Although ss-SO ${ }_{4}{ }^{2-}$ originating from sea salt particles was distributed more on the coarse particle side, it became clear that nss- $\mathrm{SO}_{4}{ }^{2-}$ was generated by the oxidation of a precursor gas such as $\mathrm{SO}_{2}$ and exists in a very small region [8]. Fig. 3 shows the correlation between nss- $\mathrm{SO}_{4}{ }^{2-}$ and $\mathrm{NH}_{4}{ }^{+}$at Nagasaki and Shanghai sites in this study. Since $\mathrm{SO}_{4}{ }^{2-}$ generated by $\mathrm{SO}_{2}$ was neutralized by $\mathrm{NH}_{3}$ in the atmosphere, it was considered that it is possible to estimate the type of $\mathrm{SO}_{4}{ }^{2-}$ present in these correlations [9].

In Shanghai, the plot on the side of the micro-particle nearly approached the slope of the straight line of 1:1. However, in the sample in Nagasaki, it approached the slope of the 1:2 line. Therefore, $\mathrm{SO}_{4}{ }^{2-}$ became excessive with respect to $\mathrm{NH}_{4}{ }^{+}$. Since the Nagasaki site was located on an upland area and was close to the mainland of China, it could be considered that there was air transport by advection from the continent. $\mathrm{NH}_{4}{ }^{+}$was never added during the transportation of the atmosphere, whereas $\mathrm{SO}_{4}{ }^{2-}$ was produced during the transport by the oxidation of $\mathrm{SO}_{2}$, so it is assumed that $\mathrm{SO}_{4}{ }^{2-}$ might be excessive. Thus, the study suggests that in Nagasaki, oxidation from $\mathrm{SO}_{2}$ to $\mathrm{SO}_{4}{ }^{2-}$ was enhanced by long-range transportation, and it changed to a chemical form of $\left(\mathrm{NH}_{4}\right)_{2} \mathrm{SO}_{4}$ or $\mathrm{NH}_{4} \mathrm{HSO}_{4}$ by reacting with $\mathrm{NH}_{3}$.

\subsection{The relationship between nss- $\mathrm{SO}_{4}{ }^{2-}$ ion and SPM concentrations}

When the concentration of SPM increased, the concentration of nss-SO ${ }_{4}^{2-}$ also increased, suggesting that sulfur oxides contribute considerably as a form of pollution in Shanghai. In addition, the concentration of nss- $\mathrm{SO}_{4}{ }^{2-}$ at the time when the PM concentration in the summer decreased considerably was similarly low, and it seemed that the concentration decreased due to the atmospheric cleaning effect from the sea in these periods. In addition, when summer and winter were compared, the overall concentration was higher in summer, but nss- $\mathrm{SO}_{4}{ }^{2-}$ in winter tended to increase in proportion to SPM concentrations.

The mass ratio of $\mathrm{NO}_{3}{ }^{-} / \mathrm{SO}_{4}{ }^{2-}$ was often used as a relative indicator of mobile sources and stationary sources in sulfur and nitrogen in the atmosphere. The high mass ratio of $\mathrm{NO}_{3}{ }^{-} / \mathrm{SO}_{4}{ }^{2-}$ indicates that the mobile source was more advantageous than the stationary sources. The ratio of $\mathrm{NO}_{\mathrm{x}}$ to $\mathrm{SO}_{\mathrm{x}}$ from gasoline and diesel fuel combustion emissions was $13: 1$ and 8:1, and the sulfur content in China's coal was around $1 \%$ if the ratio of $\mathrm{NO}_{\mathrm{x}}$ to $\mathrm{SO}_{\mathrm{x}}$ was 1:2. There is also a report about the sources of coal combustion in China [10], in which $\mathrm{SO}_{4}{ }^{2-}$ was used as an indicator of the stationary sources and $\mathrm{NO}_{3}{ }^{-}$was used as an indicator of vehicle sources (the results are shown in Fig. 2).

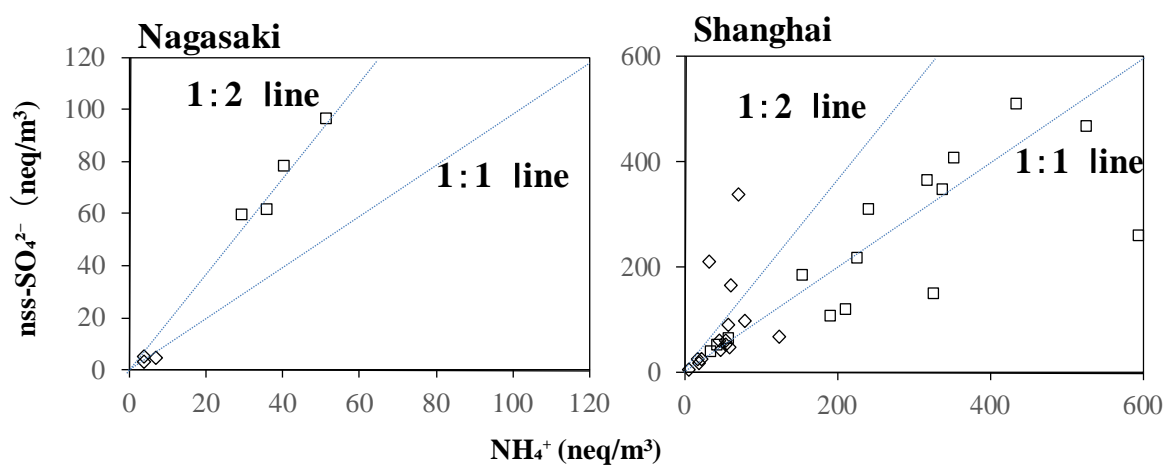

Figure 3: The correlation between concentrations of nss- $\mathrm{SO}_{4}{ }^{2-}$ and $\mathrm{NH}_{4}{ }^{+}$in the SPM of Nagasaki and Shanghai urban sites. 
In Shanghai, it was exceeded once in the winter season. In winter, $\mathrm{NO}_{3}{ }^{-}$might possibly exist as a gas without becoming particles due to high temperatures in the summer season. In the winter season, it was expected that the concentration of $\mathrm{NO}_{3}{ }^{-}$would significantly increase. In Shanghai, the concentration of $\mathrm{SO}_{4}{ }^{2-}$ was about $50 \%$ lower in summer, and the concentration of $\mathrm{NO}_{3}{ }^{-}$doubled in winter. Considering that it is present in the atmosphere in the form of $\mathrm{NH}_{4} \mathrm{NO}_{3}$ and that $\mathrm{NO}_{3}{ }^{-}$is an indicator of vehicle emission sources, this might influence the pollutant levels in the urban atmosphere in winter.

\subsection{Trace metal element contents and analysis of originating sources at Saitama, Nagasaki and Shanghai}

The concentrations of trace metal element contents of five size-segregated samples from Saitama, Nagasaki and Shanghai were analyzed. At all three sample points, natural origin elements such as $\mathrm{Fe}, \mathrm{Ca}, \mathrm{Al}, \mathrm{Mg}$ and $\mathrm{Na}$, which were commonly located in the coarse particles, and the concentrations of these elements were measured as $100 \mathrm{ng} / \mathrm{m}^{3}$ or more in Japan, while they were over $1000 \mathrm{ng} / \mathrm{m}^{3}$ in Shanghai. For $\mathrm{Zn}, \mathrm{Pb}, \mathrm{Ni}, \mathrm{Mn}, \mathrm{Cr}$, Ti and $\mathrm{Cu}$, located in both coarse and fine particles, and with anthropogenic and natural sources, the concentrations were approximately $10 \mathrm{ng} / \mathrm{m}^{3}$ in Japan, and over $100 \mathrm{ng} / \mathrm{m}^{3}$ in Shanghai. Shanghai shared the same trend as the particle size distribution of Saitama, with over several hundred times higher concentrations than those in Saitama.

The EF method is commonly used as an initial step in attempting to evaluate the strength of the crustal and non-crustal sources. The EF for any element $\mathrm{X}$ relative to crustal material is defined in eqn (2) [11]:

$$
\mathrm{EFs}=(\mathrm{X} / \mathrm{Y})_{\mathrm{air}} /(\mathrm{X} / \mathrm{Y})_{\mathrm{crust}} \text {, }
$$

where, EFs crust, $\mathrm{X}$ are the EFs of $\mathrm{X}, \mathrm{Y}$ is a reference element for crustal material, $(\mathrm{X} / \mathrm{Y})_{\text {air }}$ is the concentration ratios of $\mathrm{X}$ to $\mathrm{Y}$ in atmospheric samples and $(\mathrm{X} / \mathrm{Y})_{\text {crust }}$ is the average concentration ratio of $\mathrm{X}$ to $\mathrm{Y}$ in the crust of the earth. If EFs approached unity, crustal soils are likely to be the predominant source for the elemental X. Operationally, given local variation in soil composition, if $\mathrm{EF}$ was $>10$, the elemental $\mathrm{X}$ might have a significant fraction contributed by non-crustal sources.

The EFs in Saitama, Nagasaki and Shanghai urban areas are shown in Fig. 4. EF values in the SPM of Saitama, Nagasaki and Shanghai were over 10, which means that that these 10 kinds of elements had a large artificial influence. V, Ni, Pb, Zn, As, Sb, Se and Cd showed high $\mathrm{EF}$ values at all three sites. In addition, it was interesting that the EF values of $\mathrm{Cu}, \mathrm{Mn}$ and Sb elements, which always originate from traffic exhaust fumes in Nagasaki, were not high. And in Shanghai, the elemental Fe has a value close to 1, and Fe is always rich in coarse particles. From these results, we suggest that the air condition of Shanghai is affected by soil particles.
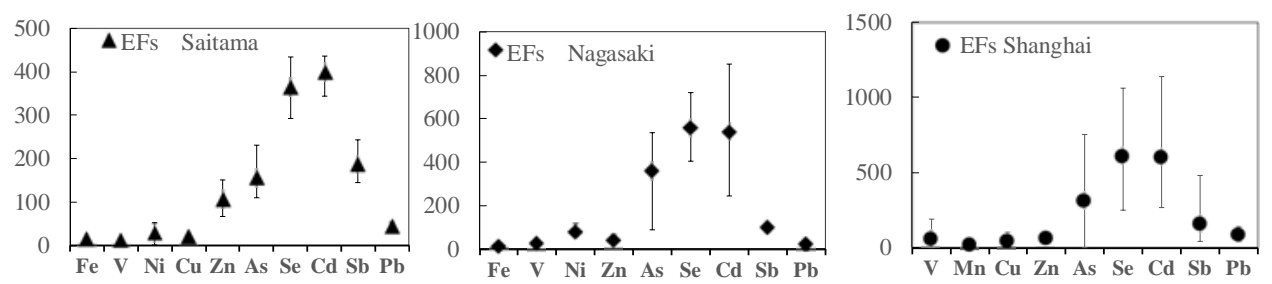

Figure 4: The crustal EF values in the SPM of Saitama, Nagasaki and Shanghai. 
In order to know more about trace elements from anthropogenic substances, Fig. 5 presents the concentrations of three groups of anthropogenic sources in three sampling sites, summarized by fine particles with a size of under $2.0 \mu \mathrm{m}$. The three groups are as follows: (a) elements considered to be heavy oil originating from ships and the like; (b) elements of coal combustion origin; and (c) road dust and traffic elements.

In group (a), elemental $\mathrm{V}$ and $\mathrm{Ni}$ were treated as the main elements for inspection. $\mathrm{V}$ was mainly used for the metallurgy of iron as an additive of various steel inclusions. It is reported that the combustion of petroleum and coal is an important source of environmental pollution by $\mathrm{V}$ and that about $90 \%$ of approximately 64,000 tons emitted to the atmosphere is burned with petroleum [12]. Regarding $\mathrm{Ni}$, artificial sources include the combustion of fossil fuels, industrial production, etc. Ni generated in the atmosphere by the combustion of fossil fuels comprises nickel sulfate and complex oxides of nickel sulfate and other metals [13]. The concentrations of V and Ni were as high as $30-50 \mathrm{ng} / \mathrm{m}^{3}$ in Shanghai, but Ni concentrations in Nagasaki during winter were higher than that in Shanghai. In comparison to Saitama, which is a similar urban area in Japan, Nagasaki presented higher concentrations in both summer and winter, as a serious result of ship-derived heavy oil, etc.

In group (b), both elemental As and Se were treated as the main elements for inspection. Although elemental As is known as a coal-burning source, it is also reported that it is emitted from incineration plants and fertilizers in urban areas. The elemental Se contained in fossil fuel becomes selenium oxide by combustion and is released into the atmosphere. However, it is reported that it might be reduced to selenium in the element state mostly due to the sulfur dioxide released. The elemental Se in the SPM of Nagasaki was double that of Saitama during winter, and also tended to be higher in Shanghai during the winter. Thus, it was inferred that this rise in Shanghai and Nagasaki during the winter was affected by coal combustion.

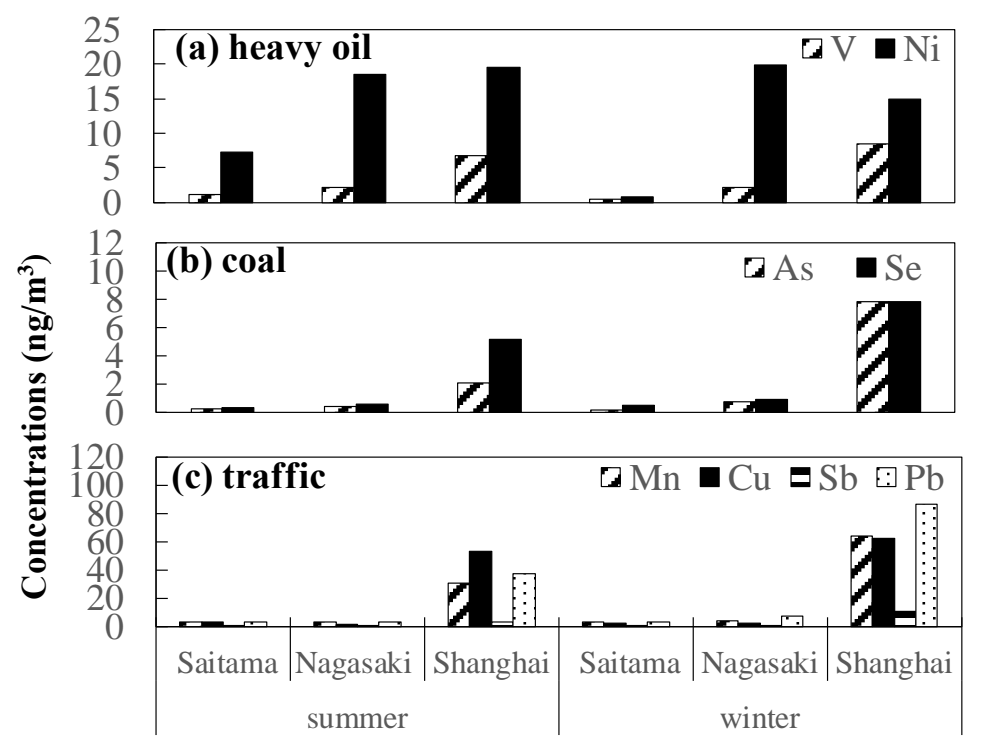

Figure 5: The concentrations of three groups of anthropogenic sources in three urban sampling sites. 
In group (c), both elemental $\mathrm{Zn}$ and $\mathrm{Mn}$ originated from the tire and brake friction of vehicles and emissions from gasoline and diesel engines. The concentrations in urban areas such as Saitama and Shanghai were very high; however, the concentrations in Nagasaki were only higher in winter, which might be affected by the pollutant particles associated with long-range transportation from the Asia mainland.

\subsection{Analysis of back-trajectory analysis using the NOAA HYSPLIT model}

Using the HYSPLIT model for back trajectories, combined with satellite images (for example, from NASA's MODIS satellites), can provide insight into whether high air pollution levels are caused by the air mass of local air pollution sources, blown in on the wind, which we calculated with typical back trajectories during our study periods, as shown in Fig. 6.

Fig. 6 shows that air masses reached Nagasaki via locations in northern and southern China, such as Shanghai during winter in Nagasaki. It is known that fossil-fuel-combustionrelated winter heating has recently become a major air quality and public health concern in northern China [14]. It has been estimated that the increase in $\mathrm{NO}_{3}{ }^{-}$and $\mathrm{SO}_{4}{ }^{2-}$ observed in Nagasaki and the increase in coal-burning indicators such as As and Se are caused by transport from these atmospheric clusters.

Fig. 6 also shows that air masses reached Shanghai mostly through northern China during winter in Shanghai - particularly in the Shandong Province, Inner Mongolia Autonomous Region, Shanxi Province, Hebei Province and Henan Province, which are located in northern China - and the coal consumption is about 300 million tons or more every year. The influence of coal-consuming elements such as the elemental As and Se overlapped in winter with long-range transportation and the local automobile emissions originating in Shanghai [15]. It is important to improve energy structures, such as renewable energy, to achieve sustainable cities in urban areas [16].
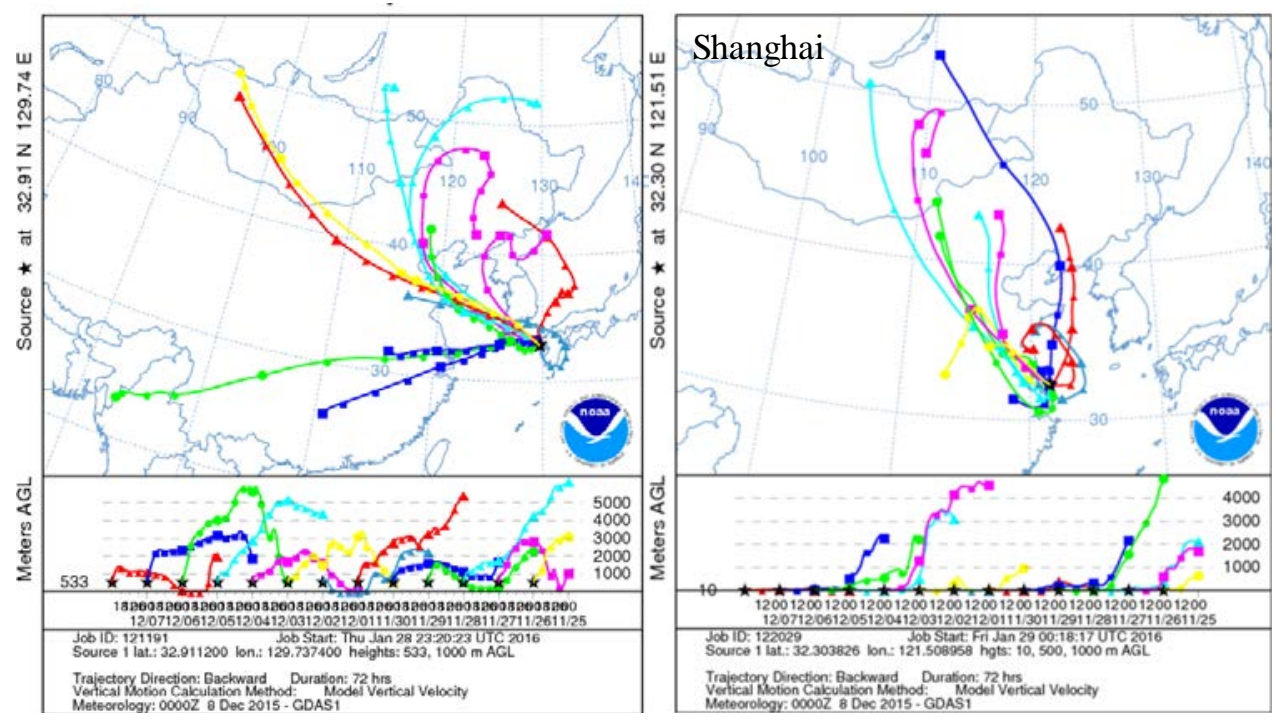

Figure 6: Typical back trajectories during our study periods, calculated using back-trajectory analysis. 


\section{CONCLUSION}

In this paper, the atmospheric inorganic compositions of Shanghai, Saitama and Nagasaki were analyzed during winter 2015. Shanghai is a metropolitan city in southern China, Saitama urban area belongs to the Tokyo metropolitan area and Nagasaki city is located in southwestern Japan. Water-soluble ions such as $\mathrm{SO}_{4}{ }^{2-}, \mathrm{NO}_{3}{ }^{-}$and $\mathrm{K}^{+}$increased in the order of Shanghai > Nagasaki > Saitama. The concentrations in Shanghai were over ten times higher than those in urban areas, confirming that serious air pollutants such as nitrogen oxides and sulfur oxides are present in Shanghai. In Shanghai, $\mathrm{NO}_{3}{ }^{-}$was an indicator of vehicle emission sources, which might influence the pollutant urban atmosphere in winter. In Nagasaki, oxidation from $\mathrm{SO}_{2}$ to $\mathrm{SO}_{4}{ }^{2-}$ was enhanced by long-range transportation, and changed to a chemical form of $\left(\mathrm{NH}_{4}\right)_{2} \mathrm{SO}_{4}$ or $\mathrm{NH}_{4} \mathrm{HSO}_{4}$ by reacting with $\mathrm{NH}_{3}$. Considering that it is present in the atmosphere in the form of $\mathrm{NH}_{4} \mathrm{NO}_{3}$ and that $\mathrm{NO}_{3}{ }^{-}$is an indicator of vehicle emission sources, this might influence the pollutant urban atmosphere in winter. Compared with Saitama, V and Ni element concentrations in Nagasaki were higher, as a serious result of ship-derived heavy oil, etc. The higher elemental As and Se concentrations in Shangahi and Nagasaki were affected by coal combustion during the winter. Analysis of elemental Zn and $\mathrm{Mn}$ concentrations revealed that the concentrations in Shanghai and Saitama urban areas were very high; however, they were only higher in Nagasaki during the winter, which might be a result of the pollutant particles associated with long-range transportation from China's mainland. The study confirms that it is possible that the urban air pollutants of fossil-fuelburning stationary sources could be transported to Japan via long-range transportation, by analysis of the NOAA HYSPLIT model. Looking at the issue of energy consumption explored in this paper, it is clear that China's energy structure needs to improve for progress to be made in sustainable development.

\section{ACKNOWLEDGEMENTS}

This study was supported by Special Funds for Innovative Area Research (grant numbers 20120015, FY2008-FY2012) and Grant-in-Aid for Scientific Research (B) (grant numbers 24310005, FY2012-FY2014; 15H05119, FY2015-FY2017; 18H03384, FY2018-FY2020) from the Japan Society for the Promotion of Science and Japanese Ministry of Education, Culture, Sports, Science and Technology.

\section{REFERENCES}

[1] Zhou, Q., China's energy production and consumption in 2015. Oil \& Gas Geology, 4, p. 1, 2016 (in Chinese).

[2] Matsumoto, K., Uyama, Y., Hayano, T. et al., Transport and chemical transformation of anthropogenic and mineral aerosol in the marine boundary layer over the western

North Pacific Ocean. Journal of Geophysical Research: Atmospheres, 109(D21), 2004.

[3] Chow, J.C. \& Watson, J.G., Review of $\mathrm{PM}_{2.5}$ and $\mathrm{PM}_{10}$ apportionment for fossil fuel combustion and other sources by the chemical mass balance receptor model. Energy \& Fuels, 16(2), pp. 222-260, 2002.

[4] Xie, K., Li, W. \& Zhao, W., Coal chemical industry and its sustainable development in China. Energy, 35(11), pp. 4349-4355, 2010.

[5] Vidal, J., WHO: air pollution has become the world's largest environmental health risk. Www.theguardian.com/environment/2014/mar/25/air-pollution-single-biggestenvironmental-health-risk-who (2015).

[6] Wikipedia, Shanghai. Cities: largest (without surrounding suburban areas). Geohive. https://en.wikipedia.org/wiki/Shanghai. Accessed on: 5 Dec. 2016. 
[7] Wikipedia, Saitama. https://en.wikipedia.org/wiki/Saitama.

[8] Xiao, R. et al., Formation of submicron sulfate and organic aerosols in the outflow from the urban region of the Pearl River Delta in China. Atmospheric Environment, 43(24), pp. 3754-3763, 2009.

[9] Sadiq, M. \& Mian, A.A., Nickel and vanadium in air particulates at Dhahran (Saudi Arabia) during and after the Kuwait oil fires. Atmospheric Environment, 28(13), pp. 2249-2253, 1994.

[10] Uematsu, M., Hattori, H., Nakamura, T., Narita, Y., Jung, J., Matsumoto, K. \& Kumar, M.D., Atmospheric transport and deposition of anthropogenic substances from the Asia to the East China Sea. Marine Chemistry, 120(1), pp. 108-115, 2010.

[11] Gao, Y., Nelson, E.D., Field, M.P. et al., Characterization of atmospheric trace elements on PM2. 5 particulate matter over the New York-New Jersey harbor estuary. Atmospheric Environment, 36(6), pp. 1077-1086, 2002.

[12] Sadiq, M. \& Mian, A.A., Nickel and vanadium in air particulates at Dhahran (Saudi Arabia) during and after the Kuwait oil fires. Atmospheric Environment, 28(13), pp. 2249-2253, 1994.

[13] Lin, C.C. et al., Characteristics of metals in nano/ultrafine/fine/coarse particles collected beside a heavily trafficked road. Environmental Science \& Technology, 39(21), pp. 8113-8122, 2005.

[14] Xie, K., Li, W. \& Zhao, W., Coal chemical industry and its sustainable development in China. Energy, 35(11), pp. 4349-4355, 2010.

[15] Wang, Q., Kobayashi, K., Lu, S., Nakajima, D., Wang, W., Zhang, W., Sekiguchi, K. \& Terasaki, M., Studies on size distribution and health risk of 37 species of polycyclic aromatic hydrocarbons associated with fine particulate matters collected in the atmosphere of a suburban area of Shanghai city, China. Environmental Pollution, 214, pp. 149-160, 2016.

[16] Wang, Q., Itoh, S. \& Lu, S., Reduction of fine particles exhausted from small-size combustor using agricultural waste residue by controlling burning temperatures. International Journal of Sustainable Development and Planning, 9(5), pp. 717-726, 2014. 